\title{
Efectos del origen social familiar en el logro educativo en el nivel superior en Argentina y México. Caminos diferentes, desigualdades similares ${ }^{1}$
}

\author{
Social origin effects in higher education attainment in Argentina \\ and México. Different paths, similar inequalities
}

\section{Pablo Dalle}

Investigador del CONICET

Instituto de Investigaciones Gino Germani

Universidad de Buenos Aires

E-mail: pablodalle@gmail.com

\section{Paula Boniolo}

Investigadora del CONICET

Instituto de Investigaciones Gino Germani

Universidad de Buenos Aires

E-mail: pboniolo@sociales.uba.ar

\section{José Navarro-Cendejas}

Profesor Investigador Cátedras CONACYT

Centro de Investigación y Docencia Económicas (CIDE)

E-mail:jnavarro78@gmail.com

\footnotetext{
${ }^{1}$ This article was elaborated in the context of INCASI Network, a European project that has received funding from the European Union's Horizon 2020 research and innovation programme under the Marie Skłodowska-Curie GA No 691004 and coordinated by Dr. Pedro López-Roldán. This article reflects only the author's view and the Agency is not responsible for any use that may be made of the information it contains.
} 


\begin{abstract}
Resumen: El artículo analiza la evolución de la desigualdad de oportunidades de logro del nivel de educación superior en Argentina y en México según origen social familiar a través de cohortes de nacimiento. Se indaga la influencia de tres factores vinculados a desigualdades de origen: clase social, nivel educativo y región de nacimiento o socialización. Se realiza un análisis estadístico de dos fuentes secundarias: la ENES-PISAC 2015 para Argentina y el Módulo de Movilidad Social 2016 de INEGI para México. Las pautas observadas nos permiten apoyar la tesis de Hout y Raftery (Maximally Maintained Inequality), en ambos países el nivel de expansión del nivel superior, en Argentina una expansión que se desarrolló más tempranamente y luego se estancó, y en México una expansión más tardía pero progresiva, fue insuficiente para reducir la desigualdad de oportunidades de logro vinculadas al origen social familiar.
\end{abstract}

Palabras clave: Logro educativo, Desigualdad de oportunidades, Educación superior

\begin{abstract}
The article analyzes the evolution of the inequality of opportunities of higher education attainment in Argentina and Mexico according to social origin towards 2015, through cohorts born between 1952 and 1986. The influence of three factors linked to inequalities of origin is investigated: social class, educational level and region of residence at birth and infancy. A statistical analysis is applied of two sources: ENES-PISAC 2015 survey for Argentina and the 2016 Social Mobility Module of INEGI for Mexico. The observed patterns allow us to support the thesis of Hout and Raftery (Maximally Maintained Inequality): in both countries the expansion of the educational upper level, in Argentina an expansion that developed earlier and then stagnated, and in Mexico a further expansion late but progressive, would have be insufficient to reduce the inequality of attainment linked to family social origin.
\end{abstract}

Key Words: Educational attainment, Inequality of opportunities, Higher education 


\title{
Efectos del origen social familiar en el logro educativo en el nivel superior en Argentina y México. Caminos diferentes, desigualdades similares
}

\author{
Social origin effects in higher education attainment in Argentina and \\ México. Different paths, similar inequalities
}

\section{Introducción}

La expansión del volumen de población con educación superior es considerada, por diversas razones, una meta central. En primer lugar, porque constituye un medio para promover el desarrollo económico en tanto brinda herramientas para incrementar las habilidades de los trabajadores según los requerimientos del sistema productivo y de las nuevas tecnologías incorporadas, y en tanto promueve a la vez la innovación y el desarrollo científico-tecnológico. Aunque los países latinoamericanos históricamente experimentaron ciertas asincronías entre el ritmo de expansión de la educación superior y la creación de espacios en la cúspide de la estructura ocupacional, provocando "emigración de talentos" hacia países más desarrollados, no puede negarse que la expansión de educación superior, en especial la universitaria, es una herramienta para promover el desarrollo, al menos porque una proporción importante de egresados universitarios persiste en encontrar (o generar) oportunidades en sus países de origen.

Segundo, la educación universitaria ha sido concebida como uno de los canales principales, y el más valorado en términos aspiracionales, de ascenso a las clases medias para una proporción amplia de familias con orígenes en clases populares. Estas familias soñaron y sueñan con que sus hijos/as sean profesionales, porque ello significa la llave de acceso a ocupaciones mejor remuneradas, pero también una conquista de "estatus social".

Tercero, es una herramienta para construir una sociedad "mesocrática": de amplias clases medias, ideario vinculado a la construcción de sociedades más equitativas (Germani y Sautu, 1965).

Por estas razones, la pregunta sobre cuán abierto es el sistema superior de un país a las personas con orígenes en clases populares o clases medias bajas cobra central relevancia. De manera similar, teniendo como meta societal una perspectiva de desarrollo integral de los países, resulta relevante conocer en qué medida las oportunidades de graduación del 
nivel de educación superior están distribuidas con equidad entre distintas regiones de cada país.

Este artículo realiza una primera aproximación al estudio de la estratificación del logro educativo de nivel superior en Argentina y México. Para situar la problemática en perspectiva temporal y comparativa reseñamos algunas cifras sobre la evolución del nivel de educación de la población. En Argentina, los datos del Censo Nacional de Población y Vivienda muestran que entre 1990 y 2010 el porcentaje de población mayor de 25 años con nivel superior completo (universitario y terciario) se incrementó de 8,2\% a 15,6\%, la población que finalizó el nivel secundario y no continuó estudios superiores creció de $13,9 \%$ a $21,4 \%$ y la población con nivel superior incompleto creció de 3,5\% a 6,1\%. Para el mismo período, en México la educación superior (sin distinguir entre nivel completo e incompleto) creció de $10 \%$ a $18 \%$, la secundaria completa de $8 \%$ a $20 \%$ y la media superior de $10 \%$ a $15 \%$. Si bien estas pautas muestran un crecimiento del nivel de educación formal de la población en ambos países, en perspectiva comparativa, la situación de Argentina y México no es tan favorable: en 2015 la población de 25 a 64 años con nivel superior completo (terciario y universitario) alcanzaba 19,9\% en Argentina (ENES-PISAC) y 16,3\% en México, cifras sustancialmente menores que la de los países más desarrollados (alrededor del $40 \%$ ) y países de desarrollo reciente como España $(35,1 \%)$ aunque mayor que Brasil (14,3\%) (OCDE, 2016).

En México, la expansión de la educación secundaria y superior ocurrió en una etapa posterior a la reportada en Argentina, sin embargo, en las últimas décadas tuvo un ritmo de crecimiento mayor generando cierta convergencia en el nivel educativo de la población entre ambos países, en particular en las cohortes más jóvenes. A pesar del crecimiento exponencial en el número de estudiantes durante las últimas 5 décadas, en términos de la población total mexicana, la cobertura de educación superior está por debajo tanto de países del entorno latinoamericano como con respecto a los países más desarrollados (MaldonadoMaldonado y Mejía, 2018). Argentina, en contraste, tiene una matrícula elevada en el nivel universitario en perspectiva comparativa, pero la tasa de graduación -tomando como base al total de estudiantes que ingresa a la universidad- es muy baja, alcanza apenas el $30 \%$ mientras que Chile, Brasil y México logran graduar más de la mitad de quienes ingresan a la universidad y en los países más desarrollados la tasa de graduación es superior al $70 \%$ (Guadagni, 2018). 
El objetivo del artículo es analizar la incidencia de factores vinculados al origen social familiar (clase social, nivel educativo y región de nacimiento o socialización) en la desigualdad de oportunidades de logro educativo en el nivel superior (universitario y terciario) en Argentina y en México en la segunda década del siglo XXI. En este marco general, constituye un eje central de interés indagar la evolución del nivel de desigualdad de oportunidades a través de cohortes de nacimiento.

La estructura del artículo es la siguiente: primero se describe el enfoque teórico propuesto a partir de los estudios clásicos sobre desigualdad de oportunidades según clivajes de estratificación social. A continuación, se realiza una breve reconstrucción del debate en el campo de estudios de estratificación social y logro educativo en Argentina y México a partir del cual elaboramos las preguntas de investigación. Posteriormente se describen las fuentes de datos y la estrategia metodológica. Luego, se analiza la evolución de los porcentajes de población con nivel superior completo según clase social de origen y nivel educativo familiar por cohortes. Esta sección se completa con la descripción del porcentaje de población con nivel superior completo según regiones en Argentina y México con el objeto de brindar un panorama de desequilibrios regionales. En la sección siguiente se presenta la evolución en el tiempo de la desigualdad de oportunidades educativas a través de la aplicación de modelos de regresión logística multivariados, dicho análisis permite captar el efecto neto de las variables adscriptas mencionadas en el logro de títulos de nivel superior. En las reflexiones finales, buscamos recuperar una visión de conjunto de las pautas halladas en ambos países en perspectiva comparativa.

\section{Enfoque teórico. Hacia un análisis multivariado del logro educativo.}

\section{Desigualdad de clase y logro educativo}

Esta investigación se enmarca en el campo de estudio sobre estratificación social y logro educativo. La preocupación central en este campo consiste en indagar en qué medida el logro educativo está asociado a las características adscriptivas de las personas (la clase social de origen, la ascendencia étnica, el nivel de educación de la familia de origen, el lugar de nacimiento, etc.). Una sociedad es considerada más abierta en la medida en que las probabilidades de acceso a las posiciones educativas que implican mayores recompensas (económicas, pero también de prestigio social) dependen menos del peso del origen social, lo que se supone abre espacio para el predominio de factores meritocráticos como las habilidades y el esfuerzo. Dentro de la variedad de enfoques teóricos sobre estratificación 
social, este estudio asume una perspectiva que plantea que la desigualdad de oportunidades está relacionada con la desigualdad de posiciones, referida esta última a la distribución de condiciones de vida entre grupos. El tipo de políticas de Estado puede contribuir a "nivelar el terreno" para disminuir la desigualdad de oportunidades de logro educativo a través de la disminución de la desigualdad de condiciones entre clases sociales (Goldthorpe, 2016).

Los estudios pioneros enfocados desde una perspectiva estructural-funcionalista plantearon que la desigualdad de oportunidades de logro educativo se reduciría en el tiempo porque la expansión del sistema educativo, vinculada a procesos de desarrollo económico, produce una disminución del peso de factores vinculados al origen social (entre los que se destaca el origen de clase) en las probabilidades de alcanzar los niveles de escolaridad más altos. En contraste con este enfoque optimista inicial, estudios comparativos posteriores de gran escala mostraron pautas de desigualdad persistente de logro educativo según orígenes de clase, lo cual implicaría que el crecimiento global de la matrícula educativa no habría contribuido a nivelar oportunidades educativas entre las clases sociales de manera significativa (Jorrat, 2010; Rodríguez, 2016). En este campo de estudios se debaten en la actualidad tres hipótesis:

i) La primera denominada "selectividad social creciente" fue elaborada por Mare (1980) y refiere a que el peso del origen social es mayor en las transiciones educativas iniciales que en las más avanzadas porque las personas de clases populares o clase media baja que alcanzan niveles educativos altos presentan una selectividad social por un conjunto de características no observadas (habilidades, expectativas, motivación, apoyo familiar, etc.), que les permiten compensar sus desventajas socioeconómicas frente a quienes tienen orígenes más privilegiados.

ii) La segunda hipótesis conocida como "Desigualdad máxima mantenida" fue desarrollada por Hout y Raftery (1993), quienes plantearon que la expansión educativa incorpora en orden secuencial a las clases sociales desde las más altas a las más bajas. Todas las clases van incrementando su participación relativa en los niveles de educación progresivos, pero se mantiene el nivel de desigualdad relativo entre ellas en la graduación del nivel más elevado. Son las clases privilegiadas las que primero se benefician de la expansión de la oferta educativa y de políticas de equidad que tienen como meta la incorporación en un determinado nivel de estudiantes provenientes de clases populares. La brecha de desigualdad permanece, o incluso se expande, hasta que la demanda de las clases más 
privilegiadas se satura, esto abre intersticios en el sistema para una reducción de la desigualdad de oportunidades de clase.

iii) Esta hipótesis fue criticada por Lucas (2001) que propuso la nueva hipótesis de "Desigualdad mantenida efectiva", según la cual la desigualdad no solo se produce en términos verticales entre niveles sino también en términos horizontales en el mismo nivel, según la calidad educativa y el prestigio social de las instituciones y los títulos que otorgan. Así, a pesar de la expansión educativa, las desigualdades de origen no son sólo cuantitativas en cuanto al nivel alcanzado, sino que también se expresan a través de ventajas cualitativas.

iv) Podemos agregar una cuarta hipótesis vinculada al papel decisivo del capital cultural, por encima de las diferencias socio-económicas, en la reproducción de desigualdades en el sistema educativo. De manera resumida este enfoque plantea que la desigualdad persistente es el resultado de que las clases privilegiadas tienden a perpetuar la trasmisión de capital cultural a través de exámenes que buscan legitimar la cultura meritocrática propia de sus ámbitos de sociabilidad y a través del valor de los títulos, directamente proporcional a su exclusividad: valen más cuanto más excluyentes son (Bourdieu y Passeron, 2003 [1964]).

En este estudio acotamos nuestra exploración a las hipótesis 1, 2 y 4. Con relación a la hipótesis 4 nos aproximaremos a indagarla a través de incluir el nivel educativo del hogar de origen como una variable diferenciada de la posición de clase social.

\section{El papel del territorio en la desigualdad educativa}

La desigualdad de oportunidades educativas no sólo debe entenderse desde una perspectiva de clase social, sino también a través de otras dimensiones como la territorial. Los territorios son espacios socio-geográficos atravesados por relaciones de poder y dominación que generan una estructura de oportunidades desigual que condiciona las trayectorias de vida de sus habitantes (Massey y Denton, 1988; Ariza y Solís, 2009).

El logro educativo refleja la culminación de trayectorias escolares que traen consigo ventajas y desventajas de orígenes sociales, territoriales y del tipo de instituciones en el que se insertan las personas que se van acumulando a lo largo del tiempo. El territorio tiene un papel importante en la estructuración de la desigualdad de oportunidades, ya que las distintas regiones del país presentan desiguales ofertas escolares, referidas tanto a la cantidad de establecimientos como a la cualidad, características de gestión, tipo de establecimiento educativo, orientación pedagógica, etc. (Kaztman, 2001). Estas (des)ventajas son potenciadas por procesos de segregación socio-residencial que traen 
como consecuencia circuitos educativos diferenciados que limitan las posibilidades de socialización entre las clases y que tienen impacto en las trayectorias educativas -como en las pautas abandono y rezago escolar (Boniolo y Najmías, 2018)- y se cristalizan en el ingreso al mercado laboral.

El lugar de residencia ha cobrado relevancia en los estudios y se ha convertido en un elemento que refuerza la condición de clase social, pero lo excede porque provee un entorno de oportunidades y limitaciones a las familias que allí habitan que potencia o restringe el marco de opciones de la clase social de origen (Kaztman, 2001; Rodríguez y Arriagada, 2004; Svampa, 2002). El tipo de oferta de servicios de salud, educación, transporte, infraestructura y los espacios de sociabilidad vinculados a un territorio condiciona el acceso a diversos capitales (económico, cultural, social y simbólico) por lo que contribuye a los procesos de formación de clase social pero también trasciende a las clases sociales implicando efectos propios en las oportunidades de vida.

\section{Estratificación social y educación superior en Argentina y México: estudios precedentes y preguntas de investigación.}

El estudio pionero de Germani y Sautu (1965) mostró que la universidad pública en Argentina constituía un sistema permeable al ingreso de estudiantes provenientes de la clase media baja y las clases populares en el marco de una sociedad dinámica. Alrededor de 1950 la tasa de estudiantes universitarios por cada diez mil habitantes de Argentina se ubicaba en el tercer puesto a nivel mundial (7,7 cada mil), una posición elevada en relación a otros indicadores de desarrollo del país. Entre las posibles causas se destacaba la alta proporción de clases medias y el alto nivel de aspiraciones hacia el ascenso a través de la educación en sociedades de amplia movilidad social ascendente (Germani y Sautu, 1965). Además del nivel alto de expansión, el sistema de educación superior en Argentina era más abierto en comparación al de otros países en la década de 1960. Los porcentajes de ingreso en la Universidad de Buenos Aires (UBA) de estudiantes de origen de clase popular $(18,4 \%)$ y de clase media baja $(46,2 \%)$, eran considerablemente superiores a los registrados en otras universidades de referencia de Europa. La composición de la matrícula de la Universidad de La Plata y de la Universidad del Sur mostraba un menor acceso de estudiantes de dichos orígenes en comparación con la UBA, aunque también eran niveles altos en la comparación internacional.

La investigación sobre estratificación y oportunidades educativas fue retomada por Jorrat (2010 y 2016) utilizando las encuestas CEDOP-UBA. Sus investigaciones muestran que pese a la expansión del sistema educativo las desigualdades de logro educativo según 
orígenes sociales no se redujeron, sino que se mantuvieron constantes en el tiempo. A su vez, destacó una mayor influencia de los antecedentes educativos de la madre que del padre en los destinos educativos de los hijos. La investigación de Alcoba (2014) apoya la pauta de desigualdad persistente y profundiza a la vez en la identificación de circuitos educativos públicos y privados que refuerzan la desigualdad de clase. Esta pauta de desigualdad constante de oportunidades educativas según origen de clase a través de cohortes se muestra robusta, Quartulli (2016) encontró una tendencia similar con la Encuesta de la Deuda Social de Argentina de 2010.

Haciendo foco en el logro educativo en el nivel universitario en Argentina, Rodríguez (2016) también halló pautas consistentes con la persistencia del nivel de desigualdad y destacó que la mayor reproducción entre orígenes y destinos educativos se cristaliza en la base y en la cúspide de la estructura educativa, siendo mayor la desigualdad de oportunidades entre los varones. Plotno (2015) aporta evidencias que profundizan las pautas precedentes, mostrando que el efecto de la educación de la familia de origen aumenta en las cohortes más jóvenes; y que, aunque la clase social de origen tiene un efecto menor que la educación familiar, continúa influyendo en las oportunidades de acceso y graduación de la Universidad en todas las cohortes de edad.

El estudio comparativo de Fachelli, Molina y Torrents (2015) sobre ingreso a la universidad de los jóvenes de 20 a 24 años aporta evidencias de una brecha mayor entre las clases medias y la clase trabajadora en Argentina en relación a España y México. Esta pauta resulta contradictoria, ya que el sistema universitario público en Argentina es gratuito y de ingreso irrestricto y abre una interesante línea de investigación sobre las posibles causas.

En México, estudios realizados desde la segunda mitad del siglo pasado encontraron una influencia considerable del origen social en el logro educativo (aunque con tendencia a su reducción). Balán, Browning y Jelin (1977), replicando el modelo clásico de Blau y Duncan, mostraron que la educación constituía el factor más determinante para el logro ocupacional, mayor incluso que el efecto directo del origen social. En años más recientes, con diferentes metodologías y definición de cohortes, Binder y Woodruff (2002), Torche (2010) y De Hoyos et al., (2010), encontraron un aumento en la movilidad educativa intergeneracional en la segunda mitad del siglo XX, aunque con una tendencia a su disminución en las cohortes más jóvenes (1972-1981, en el caso de los últimos dos estudios). La disminución de la movilidad educativa de las cohortes más recientes fue contradicha por el estudio de Yalonetzky (2017), quien midió por distintos métodos la 
movilidad educativa sin encontrar una interrupción en el patrón de aumento de la movilidad, incluso para ambos sexos.

Los estudios de movilidad intergeneracional de clase muestran que tanto Argentina como México se sitúan entre los pocos ejemplos de países que experimentaron cambios hacia un cierre de la estructura de clases, esto es, un incremento del peso del origen de clase social en el destino de clase alcanzado (en México: Cortés y Escobar Latapí, 2007 y Solís, 2016 particularmente en la cohorte más joven; en Argentina: Jorrat y Benza, 2016 entre fluidez constante y mayores rigidices a través de las cohortes entre los varones y Dalle, 2018, evidenciando cambios a través de las cohortes de varones hacia mayores obstáculos a la movilidad social de larga distancia entre las clases populares y la clase de servicios). En este estudio, acotamos nuestra indagación a los efectos de variables adscriptas en el logro educativo, pero con la mirada puesta en dilucidar la evolución del nivel de apertura de la estructura de estratificación de clases, de hecho, una mayor equidad en el logro educativo puede favorecer la fluidez social.

A pesar de la importancia del territorio en la configuración de la desigualdad de oportunidades señalada en la sección precedente, en América Latina son escasas las investigaciones que vinculan aspectos del proceso de estratificación social como la movilidad social intergeneracional o el logro educativo con la dimensión territorial, más bien se suele considerar al territorio como un escenario donde los procesos de estratificación tienen lugar, una forma de contextualizarlos, más que un objeto en sí mismo. En México se destaca el estudio de Solís y Puga (2011) mostrando un efecto del nivel socio-económico de la zona residencial en el proceso de logro de estatus. En Argentina destacan el de Alcoba (2014) y Boniolo y Estévez Leston (2007). El primero indaga la influencia del lugar de residencia en la desigualdad de oportunidades educativas, mostrando mayores probabilidades de acceso a los niveles secundario y universitario, y de asistencia a instituciones privadas en ambos niveles para quienes residen en Área Metropolitana de Buenos Aires en comparación con el resto del país. En nuestro estudio buscamos profundizar el examen del efecto de la desigualdad territorial con una clasificación más amplia de regiones que permitan captar mejor la heterogeneidad territorial. El segundo estudio constata un efecto neto de la región de socialización en las chances relativas de movilidad social intergeneracional ascendente controlando por otras variables de tipo adscripto. En base a estas pautas, consideramos relevante indagar la influencia del territorio en el logro de títulos de nivel superior. 
La reconstrucción de estudios precedentes en ambos países indica que Argentina y México experimentaron cierto cierre de la estructura de estratificación social en las últimas décadas. El desarrollo de encuestas recientes en ambos países (ENES-PISAC y MMSI-INEGI: 2016) nos permite actualizar la indagación sobre desigualdades de clase en el logro educativo y la incorporación de otras variables de estratificación como la educación familiar y la región de nacimiento. Los interrogantes que guían el estudio son: ¿Qué impacto tuvo en ambos países el nivel de expansión de la educación superior desde el último cuarto del siglo XX en las probabilidades de graduación de los hijos/as de padres de clase popular? ¿Dicha expansión ha sido suficiente para lograr disminuir la desigualdad de orígenes de clase en las probabilidades de graduación? ¿Cuánto incide el origen educativo familiar en las probabilidades de graduación del nivel superior? ¿La clase social de origen tiene un peso específico diferenciado del efecto del origen educativo familiar? ¿En qué medida la desigualdad de oportunidades educativas está asociada con la región de nacimiento? ¿Esta variable vinculada a la desigualdad de desarrollo regional tiene peso propio? ¿El peso de estas variables y su dinámica temporal es similar en ambos países? En suma, ¿desde una perspectiva temporal y comparativa en qué medida se avanzó en las últimas décadas en la democratización del acceso a oportunidades educativas en Argentina y México?

\section{Datos y métodos}

En este trabajo se utiliza una metodología cuantitativa combinando el análisis de datos provenientes de la Encuesta Nacional sobre la Estructura Social (ENES), llevada a cabo por el Programa de Investigación sobre la Sociedad Argentina Contemporánea (PISAC), del Ministerio de Ciencia y Tecnología Argentina 2015 y del Módulo de Movilidad Social (MMSI), 2016 del Instituto Nacional de Estadística y Geografía (INEGI), México. La ENES relevó información sobre 8.265 hogares y 27.609 personas en localidades urbanas (de más de 2.000 habitantes) de todo el país. La encuesta MMSI relevó información sobre 32.481 hogares en localidades urbanas (2.500 habitantes y más) y rurales (menores a 2.500 habitantes) de todo el país. Ambas encuestas cuentan con un diseño muestral de tipo probabilístico, por lo cual es posible realizar estimaciones al universo de estudio.

El universo corresponde a los Principales Sostenes del hogar (PSH) de ambos sexos entre 30 y 64 años, de todos los niveles educativos que residían en la Argentina urbana y México total país en 2015 y 2016 respectivamente ${ }^{2}$. El total de la muestra de Argentina y México,

\footnotetext{
${ }^{2}$ Hemos extendido el límite inferior de edad a 30 años, en vez de considerar el recorte clásico de 25 a 65 años de los estudios de movilidad social o de logro educativo, porque una proporción considerable de estudiantes de nivel superior se gradúa entre los 25 y 30 años, principalmente en el caso de Argentina.
} 
una vez realizado el recorte de edad y eliminar casos sin información sobre el origen social familiar es de 4.505 y 9.985 casos respectivamente.

La estrategia de análisis consiste en el uso de técnicas descriptivas basadas en tablas de contingencia y técnicas inferenciales a través de modelos de regresión logística binaria multivariada. En la tabla 1 se resume la categorización de las variables utilizadas.

\section{Tabla 1: Descripción de las variables utilizadas}

\begin{tabular}{|c|c|c|c|c|c|}
\hline \multirow{2}{*}{ Variable dependiente } & \multirow{2}{*}{$\begin{array}{c}\text { Nivel } \\
\text { educativo del } \\
\text { PSH } \\
\end{array}$} & \multicolumn{4}{|c|}{ Finalizaron estudios superiores (terciarios y universitarios). } \\
\hline & & \multicolumn{4}{|c|}{ Resto: No finalizaron estudios superiores } \\
\hline \multirow{21}{*}{ Variables independientes } & \multirow{3}{*}{$\begin{array}{l}\text { Clase de } \\
\text { origen* }\end{array}$} & \multicolumn{4}{|c|}{ Clase de servicios y empleadores } \\
\hline & & \multicolumn{4}{|c|}{ Clase intermedia } \\
\hline & & \multicolumn{4}{|c|}{ Clase obrera } \\
\hline & \multirow{4}{*}{$\begin{array}{c}\text { Nivel } \\
\text { educativo de } \\
\text { origen }\end{array}$} & \multicolumn{4}{|c|}{ Hasta secundario incompleto } \\
\hline & & \multicolumn{4}{|c|}{ Secundario completo } \\
\hline & & \multicolumn{4}{|c|}{ Terciario completo } \\
\hline & & \multicolumn{4}{|c|}{ Universitario completo. } \\
\hline & \multirow{4}{*}{ Cohortes } & \multirow{4}{*}{ 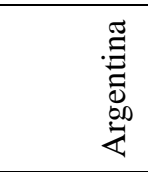 } & 1950-1959 & \multirow{4}{*}{ 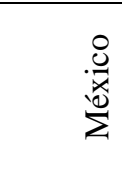 } & $1952-1959$ \\
\hline & & & 1960-1968 & & $1960-1968$ \\
\hline & & & 1969-1977 & & 1969-1977 \\
\hline & & & $1978-1985$ & & $1978-1986$ \\
\hline & & \multicolumn{2}{|c|}{ Argentina } & \multicolumn{2}{|c|}{ México } \\
\hline & \multirow{9}{*}{$\begin{array}{c}\text { Región de } \\
\text { nacimiento } \\
\text { (Argentina) o } \\
\text { de Residencia } \\
\text { a los } 14 \text { años } \\
\text { (México) }\end{array}$} & \multicolumn{2}{|c|}{$\begin{array}{l}\text { CABA (Ciudad Autónoma de } \\
\text { Buenos Aires) }\end{array}$} & \multicolumn{2}{|c|}{ Ciudad de México } \\
\hline & & \multicolumn{2}{|c|}{$\begin{array}{l}\text { PGBA (24 partidos de Gran } \\
\text { Buenos Aires) }\end{array}$} & \multicolumn{2}{|c|}{ Bajío occidente } \\
\hline & & \multicolumn{2}{|c|}{ Cuyo } & \multicolumn{2}{|l|}{ Centro } \\
\hline & & \multicolumn{2}{|l|}{ Pampeana } & \multicolumn{2}{|c|}{ Golfo sur } \\
\hline & & \multicolumn{2}{|c|}{ Centro } & \multicolumn{2}{|c|}{ Frontera norte } \\
\hline & & \multicolumn{2}{|c|}{ NEA (Noreste Argentino) } & & \\
\hline & & \multicolumn{2}{|c|}{ NOA (Noroeste Argentino) } & & \\
\hline & & \multicolumn{2}{|c|}{ Patagonia } & & \\
\hline & & \multicolumn{2}{|c|}{ Países limítrofes y Perú } & & \\
\hline
\end{tabular}

Nota: La variable clase social de origen se construyó sobre el esquema EGP (Erikson, Goldthorpe y Portocarrero) elaborado a partir del algoritmo de Ganzeboom. Dadas las limitaciones del tamaño muestral para un análisis multivariado se utilizó un agrupamiento de tres macro clases: clase de servicios, clase intermedia y clases populares. Esta clasificación se realizó sobre la propuesta de Dalle, Jorrat y Riveiro (2018) para medir la movilidad social vertical, que atraviesa las principales fronteras jerárquicas en la estructura de clases. Dicho esquema de clases se distancia un poco de la propuesta de Erikson y Goldthorpe (1992), en particular realizamos cuatro modificaciones tomando en consideración rasgos de la estructura de clases de las sociedades latinoamericanas actuales: i. incorporamos a los pequeños empleadores a la clase de servicios, ii. Incluimos a los trabajadores no manuales de rutina de nivel bajo (empleados de comercio) en las clases populares, iii. re-clasificamos a los trabajadores manuales cuenta propia no calificados (con frecuencia vinculados al sector informal) en las clases populares y iv. incluimos a los trabajadores autónomos rurales en las clases populares. Estos cambios permiten captar mejor la desigualdad de condiciones y de oportunidades entre clases sociales. 


\section{Resultados}

Logro educativo en el nivel superior en el marco de tendencias estructurales

En esta sección analizamos en perspectiva comparativa la dinámica temporal de la desigualdad de oportunidades de logro educativo según clase social y nivel educativo del hogar de origen. Para ello calculamos los porcentajes de graduados de nivel superior de los PSH entre 30 y 64 años, según los factores adscriptivos señalados a través de cohortes de nacimiento para Argentina (Cuadro 1) y México (Cuadro 2).

Cuadro 1. Porcentaje de población con nivel de educación superior (universitario y terciario) según origen de clase, nivel educativo de origen, controlado por cohortes de nacimiento. PSH de 30 a 64 años. Argentina, 2015

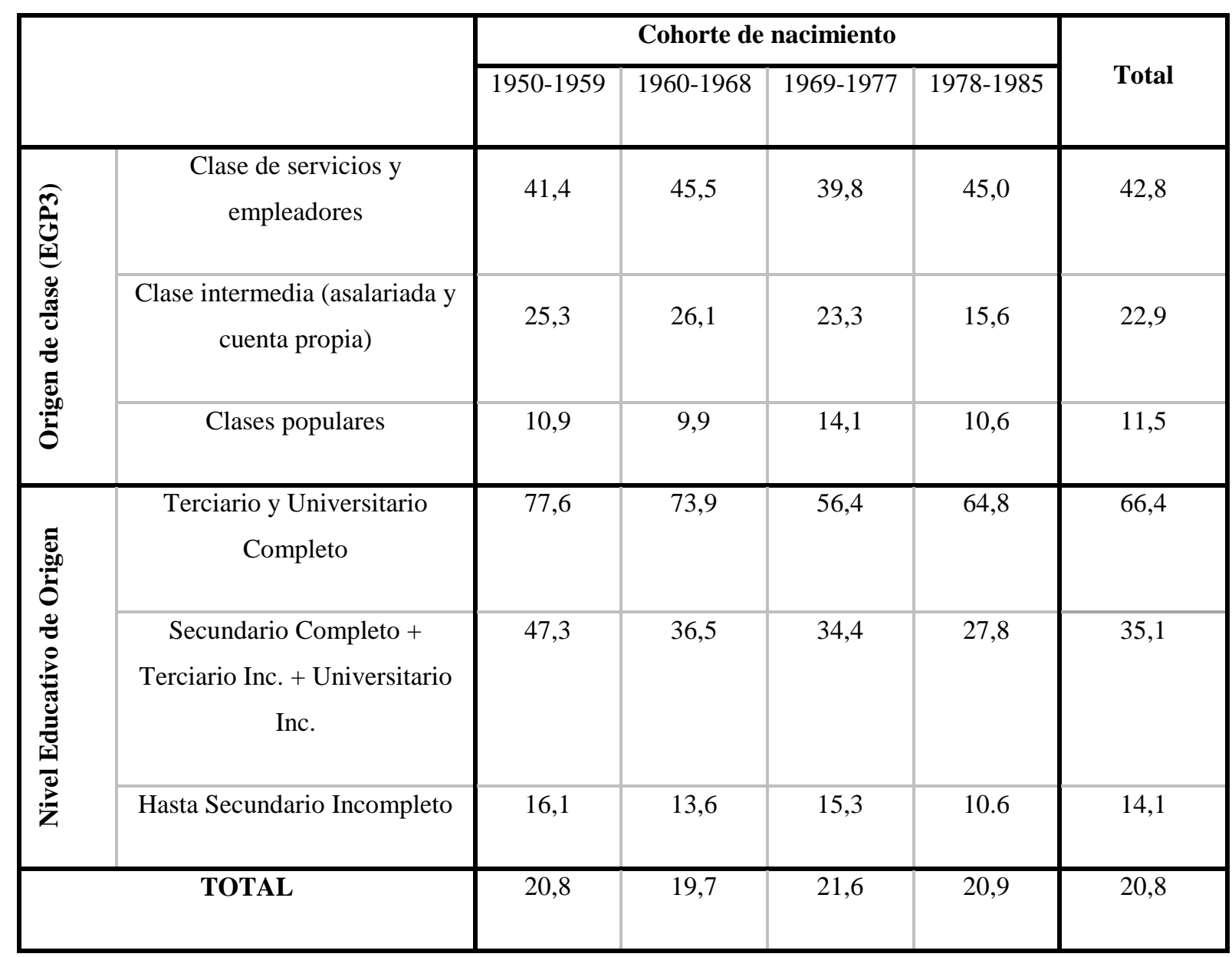

Fuente: elaboración propia en base a ENES-PISAC

En Argentina, el porcentaje de población con nivel superior completo a través de cohortes (marginal fila) se mantiene relativamente constante alrededor de $21 \%$. Esta pauta indica un estancamiento en el tiempo del volumen de población con estudios terciarios y universitarios. En México, se observa un crecimiento más pronunciado en el porcentaje de 
graduados de nivel superior en las cohortes más jóvenes respecto a las anteriores. Así, se pasa de un $15 \%$ en la cohorte de 1952-1959 a 19,5\% en la cohorte de 1978-1986.

Cuadro 2. Porcentaje de población con nivel de educación superior (universitario y terciario) según origen de clase, nivel educativo de origen, controlado por cohortes de nacimiento. PSH de 30 a 64 años. México, 2016

\begin{tabular}{|c|c|c|c|c|c|c|}
\hline & & \multicolumn{4}{|c|}{ Cohorte de nacimiento } & \multirow[b]{2}{*}{ Total } \\
\hline & & $\begin{array}{c}1952- \\
1959\end{array}$ & $1960-1968$ & 1969-1977 & $1978-1986$ & \\
\hline \multirow{3}{*}{ 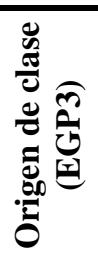 } & $\begin{array}{c}\text { Clase de servicios y } \\
\text { empleadores }\end{array}$ & 39,8 & 46,5 & 45,1 & 55,5 & 47,6 \\
\hline & $\begin{array}{l}\text { Clase intermedia } \\
\text { (asalariada y cuenta } \\
\text { propia) }\end{array}$ & 12,8 & 20,9 & 19,3 & 23,2 & 19,8 \\
\hline & Clases populares & 10,2 & 9,4 & 9,1 & 9,8 & 9,6 \\
\hline \multirow{3}{*}{ 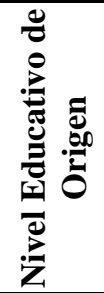 } & $\begin{array}{c}\text { Terciario y } \\
\text { Universitario Completo }\end{array}$ & 69,4 & 59,8 & 65,6 & 73,3 & 68,0 \\
\hline & $\begin{array}{c}\text { Secundario Completo + } \\
\text { Terciario Inc. }+ \\
\text { Universitario Inc. }\end{array}$ & 52,5 & 49,5 & 51,1 & 50,6 & 50,7 \\
\hline & $\begin{array}{l}\text { Hasta Secundario } \\
\text { Incompleto }\end{array}$ & 12,3 & 13,6 & 11,3 & 11,7 & 12,3 \\
\hline & TOTAL & 15,0 & 16,0 & 15,7 & 19,5 & 16,6 \\
\hline
\end{tabular}

Fuente: elaboración propia con base en MMSI, INEGI 2016.

En perspectiva temporal, el análisis de las pautas conjuntas en ambos países sugiere mayores obstáculos a la finalización del nivel de educación superior en la cohorte más reciente de quienes provienen de hogares de clase popular y clases medias no profesionales, siendo en México más marcada una tendencia progresiva al incremento de la desigualdad, sobre todo por un incremento progresivo en la graduación de quienes provienen de las clases medias privilegiadas.

Para Argentina, los datos de la encuesta ENES nos permiten obtener una primera mirada sobre la incidencia de la región de nacimiento y la región de residencia actual en el logro del nivel educativo de educación superior (Cuadro 3). 
Cuadro 3: Porcentaje de población con nivel de educación superior según región de nacimiento y región de residencia. PSH de 30 a 64 años. Argentina, 2015

\begin{tabular}{|l|c|c|}
\hline \multirow{2}{*}{ Regiones } & Lugar de Nacimiento & Lugar de Residencia \\
\cline { 2 - 3 } & \% Superior completo & \% Superior completo \\
\hline \hline CABA & 44,1 & 39,1 \\
PGBA & 20,7 & 18,3 \\
Cuyo & 16,1 & 18,5 \\
Pampeana & 21,6 & 19,0 \\
Centro & 19,2 & 20,1 \\
NEA & 12,9 & 15,3 \\
NOA & 18,9 & 19,0 \\
Patagonia & 22,5 & 23,8 \\
Países limítrofes más Perú & 11,6 & \\
\hline Total & 20,8 & 20,8 \\
\hline
\end{tabular}

Fuente: elaboración propia con base en ENES-PISAC.

Nota: Los PSH nacidos en otros países no correspondientes a América Latina fueron eliminados por la escasa cantidad de casos.

El cuadro 3 permite observar que nacer en y residir en CABA incrementa sustancialmente las oportunidades de finalizar el nivel superior; en contraste con haber nacido en el NEA, países limítrofes, Cuyo y NOA, en ese orden, aunque sin dudas la principal pauta es la amplia ventaja de los nacidos en CABA respecto del resto las regiones. Las pequeñas diferencias entre los porcentajes de graduados del nivel superior de educación entre región de nacimiento y región de residencia se deben a que las regiones con mayor nivel desarrollo relativo (ejemplo CABA y Pampeana) son receptoras de corrientes migratorias que en términos generales tienen menor nivel educativo por lo que disminuye levemente el peso relativo del grupo con mayor nivel de escolaridad, pero no son diferencias muy amplias.

En el caso de México, las regiones que se utilizan para este trabajo provienen de una adaptación propuesta por Solís y Cortés (2009), cuyo interés radica en diferenciar cuatro grandes regiones que reúnen características similares con respecto al desarrollo económico reciente, con una clara diferencia entre la región fronteriza del norte más desarrollada y los estados del sur y del golfo de México, con mayores índices de rezago. Las otras dos regiones, con resultados más heterogéneos, corresponden al centro y al bajío-occidente. Para nuestro análisis se decidió considerar una quinta región, que corresponde a la Ciudad de México, para mantener la comparabilidad con el caso argentino. Así, el cuadro 4 presenta el porcentaje de población con nivel superior completo con respecto al lugar de residencia a los 14 años y al lugar de residencia al momento de la encuesta. Se observa una clara desigualdad entre los resultados de la Ciudad de México y el resto de las regiones, en donde por décadas se concentró buena parte de la oferta educativa de nivel superior en la primera. Además, se confirma la tendencia esperada respecto a la distancia entre la región 
Frontera y la región Golfo-sur, a favor de la primera, con mayor énfasis respecto a la influencia del lugar de origen en la probabilidad de graduarse del nivel superior.

Cuadro 4: Porcentaje de población con nivel de educación superior según región de nacimiento y región de residencia. PSH de 30 a 64 años. México, 2016

\begin{tabular}{|l|c|c|}
\hline \multirow{2}{*}{ Regiones } & Lugar de Residencia a los 14 años & Lugar de Residencia \\
\cline { 2 - 3 } & \% Superior completo & \% Superior completo \\
\hline \hline Ciudad de México & 33,1 & 35,1 \\
Frontera & 18,7 & 17,6 \\
Bajío-occidente & 13,8 & 14,1 \\
Centro & 15,8 & 16,4 \\
Golfo-sur & 11,8 & 11,8 \\
\hline Total & 15,4 & 15,4 \\
\hline
\end{tabular}

Fuente: elaboración propia con base en MMSI INEGI. Los casos que reportaron residencia a los 14 años fuera de México fueron excluidos del análisis 
Factores condicionantes del logro de educación superior en Argentina y México

Las variables independientes introducidas en la sección de análisis descriptivo de la desigualdad en las probabilidades de logro de educación superior están relacionadas entre sí. A mayor nivel educativo del PSH de origen, mayor jerarquía de la posición de clase, asimismo, las regiones más desarrolladas tienen mayor proporción de hogares con orígenes en clases medias y con niveles de escolaridad más altos. Por ello, en las tablas de contingencia analizadas el efecto de cada variable independiente lleva consigo el efecto de los otros factores adscriptos estudiados. Para indagar el efecto neto de cada una de las variables independientes sobre la variable dependiente, controlando la influencia de las otras variables, es necesario realizar un modelo de regresión logística binaria multivariado (Cuadros 5 y 6 ).

En las regresiones logísticas binarias la estimación del coeficiente $\beta$ exponenciado permite conocer las chances relativas (odd ratios) de completar estudios de nivel superior contra no haber obtenido dichas credenciales educativas entre la categoría de referencia seleccionada y cada categoría de las variables independientes, controlando por las otras variables incluidas en el modelo.

Cuadro 5: Regresión logística binaria de nivel superior completo (universitario y terciario) en origen de clase, nivel educativo del PSH de origen, lugar de nacimiento y cohorte. Población de 30 a 64 años Principal Sostén del Hogar. Argentina, 2015 (Exp. Beta)

\begin{tabular}{|c|c|c|c|c|c|}
\hline Variables independientes & M 1 & M 2 & M 3 & M 4 & $\begin{array}{c}\text { M 4bis } \\
\text { Población con } \\
\text { secundario } \\
\text { completo }\end{array}$ \\
\hline \multicolumn{6}{|l|}{ Origen de clase (Ref. Clase obrera) } \\
\hline Clase de servicios y empleadores & $5,79 * * *$ & $3,00 * * *$ & $2,95 * * *$ & $2,99 * * *$ & $2,02 * * *$ \\
\hline Clase Intermedia & $2,30 * * *$ & $1,95 * * *$ & $1,92 * * *$ & $1,93 * * *$ & $1,57 * *$ \\
\hline \multicolumn{6}{|l|}{$\begin{array}{l}\text { Nivel educativo del PSH de origen } \\
\text { (Ref. Hasta secundaria incompleta) }\end{array}$} \\
\hline Secundario completo & & $2,47 * * *$ & $2,38 * * *$ & $2,54 * * *$ & $1,48 *$ \\
\hline Superior completo & & $6,62 * * *$ & $6,02 * * *$ & $6,55 * * *$ & $3,62 * * *$ \\
\hline \multicolumn{6}{|l|}{ Lugar de nacimiento (Ref. CABA) } \\
\hline PGBA & & & $0,56 * *$ & $0,57 * *$ & $0,63 *$ \\
\hline Cuyo & & & $0,38 * * *$ & $0,38 * * *$ & $0,51 * *$ \\
\hline Pampeana & & & $0,60 * *$ & $0,61 *$ & 0,70 \\
\hline Centro & & & $0,52 * * *$ & $0,51 * *$ & $0,61 *$ \\
\hline NEA & & & $0,44 * * *$ & $0,45 * *$ & 0,70 \\
\hline NOA & & & $0,61 * *$ & $0,60 * *$ & 0,89 \\
\hline Patagonia & & & 0,64 & 0,67 & 1,02 \\
\hline Países limítrofes más Perú & & & $0,31 * * *$ & $0,30 * * *$ & $0,45 *$ \\
\hline
\end{tabular}




\begin{tabular}{|c|c|c|c|c|c|}
\hline \multicolumn{6}{|l|}{$\begin{array}{l}\text { Cohorte de nacimiento } \\
\text { (Ref. 1945-1955) }\end{array}$} \\
\hline Nacidos entre 1960 y 1968 & & & & 0,88 & 0,83 \\
\hline Nacidos entre 1969 y 1977 & & & & 0,85 & 0,74 \\
\hline Nacidos entre 1978 y 1985 & & & & $0,58 * *$ & $0,51 * * *$ \\
\hline Pseudo ${ }^{2}$ & 0,087 & 0,141 & 0,151 & 0,155 & 0,082 \\
\hline $\mathrm{N}$ & 4911 & 4505 & 4505 & 4505 & 2406 \\
\hline
\end{tabular}

Notas: (1) $0=$ No accedió a títulos de nivel superior; 1 = Logró título de nivel superior.

$* * * \mathrm{p}<0,001 ; * *<0,01 ; * \mathrm{p}<0,05, \mathrm{n} / \mathrm{c}$ : no considerada.

Fuente: elaboración propia con base en ENES-PISAC

En el modelo 1 incluimos el origen de clase social bajo el supuesto de que constituye el clivaje central de desigualdad en las oportunidades de logro educativo. Utilizaremos este modelo como base para indagar en qué medida la introducción de otras variables adscriptivas aporta efectos significativos sobre las chances relativas de graduarse de la universidad. Los resultados del modelo 1 muestran que el origen de clase social está asociado significativamente con el acceso a títulos universitarios y terciarios.

Los PSH que provienen de hogares de clase de servicios o empleadores tienen 5,8 veces más chances de acceder a títulos superiores que quienes provienen de hogares obreros. Entre los PSH que provienen de hogares de clase intermedia (empleados y pequeños comerciantes) y los que provienen de hogares obreros, la desigualdad de oportunidades disminuye a 2,30 veces en favor de los primeros.

En el modelo 2, al introducir el nivel educativo del hogar de origen, observamos que, si bien se reduce el efecto de la clase de origen, ambas variables están asociadas significativamente con la desigualdad de oportunidades de la población en alcanzar credenciales de nivel superior. Los PSH que provienen de un hogar con estudios superiores completos tienen 6,6 veces más chances de obtener títulos de nivel superior que quienes provienen de hogares que no completaron el nivel secundario. Esta desigualdad se reduce a alrededor de 2,4 veces entre quienes provienen de hogares que finalizaron el nivel secundario y quienes se socializaron en hogares en los que dicho nivel no se completó. Si bien disminuye su peso, la clase de origen no deja de tener un efecto neto. En particular, se reduce el peso del origen en clase de servicios o empleadores de 5,8 a 3 veces más chances de acceder a títulos de nivel superior en relación al origen en clase obrera; ello se debe, en gran medida, a que buena parte de este efecto deriva del nivel de educación superior del PSH de origen de clase de servicios. El valor del $\mathrm{R}^{2}$ de Nagelkerke aumenta de 0,087 a 0,141 lo cual indica que el nivel educativo del hogar de origen influye de manera relevante y que tanto la clase de origen como el nivel educativo están relacionados. 
Al introducir el lugar de nacimiento (modelo 3) observamos que el origen de clase y el nivel educativo del hogar de origen disminuyen levemente su influencia, pero continúan teniendo un efecto significativo. Por su parte, la región de origen muestra un efecto neto en la desigualdad de oportunidades de logro del nivel superior. Igualando el origen de clase y el nivel educativo del hogar de origen, la población que nació en CABA tiene mayores oportunidades de alcanzar títulos universitarios y terciarios que la población que nació en las otras regiones. La incorporación de la región de nacimiento mejora levemente el grado de ajuste del modelo (el $\mathrm{R}^{2}$ de Nagelkerke pasa de 0,141 a 0,151 ). Los resultados de la regresión indican que hay una desigualdad más relevante en el logro del nivel superior por región de nacimiento en favor de los $\mathrm{PSH}$ nacidos en CABA. Al controlar por origen de clase social y nivel educativo del hogar, estos factores no serían parte de la explicación de las ventajas de CABA. Estas pueden estar vinculadas a una mayor oferta educativa, mejor entrenamiento en niveles de escolaridad previos y mayores ingresos de las familias, entre otros factores.

Por último, en el modelo 4 al introducir la cohorte de nacimiento se observa que las variables introducidas en los pasos anteriores mantienen su efecto en niveles muy similares y de manera significativa. La introducción de una perspectiva temporal a través de las cohortes de nacimiento muestra que la población PSH nacida en la cohorte más joven tuvo menores oportunidades de obtener títulos superiores controlando por origen de clase, nivel educativo del PSH de origen y lugar de nacimiento. Sin embargo, es importante advertir que la incorporación de la variable cohorte de nacimiento no muestra influencia en el grado de ajuste del modelo (el $\mathrm{R}^{2}$ de Nagelkerke pasa de 0,151 a 0,155 ).

A fin de indagar si el efecto de los orígenes sociales se debilita a medida que se avanza en las transiciones entre niveles educativos, hemos aplicado una versión completa del modelo de regresión logística a la población que finalizó el nivel secundario y estaba en condiciones de ingresar al nivel superior. Los resultados del modelo muestran que, si bien los efectos de las variables consideradas disminuyen, todas mantienen un peso significativo mostrando una injerencia importante del origen social familiar en la desigualdad de oportunidades de logro del nivel superior. Analizamos a continuación qué sucede en México para comparar tendencias y pautas. 


\section{Cuadro 6: Regresión logística binaria de nivel superior completo (universitario y} terciario) en origen de clase, nivel educativo del PSH de origen, lugar de nacimiento y cohorte. Población de 30 a 64 años. Principal Sostén del Hogar. México, 2016 (Exp. Beta)

\begin{tabular}{|c|c|c|c|c|c|}
\hline Variables independientes & M 1 & M 2 & M 3 & M 4 & $\begin{array}{l}\text { M 4bis } \\
\text { Población con } \\
\text { secundario } \\
\text { completo }\end{array}$ \\
\hline $\begin{array}{l}\text { Origen de clase (Ref. Clase obrera) } \\
\text { Clase de servicios y empleadores } \\
\text { Clase Intermedia }\end{array}$ & $\begin{array}{l}8,56 * * * \\
2,33 * * *\end{array}$ & $\begin{array}{l}3,51 * * * \\
1,92 * * *\end{array}$ & $\begin{array}{l}3,38 * * * \\
1,84 * * *\end{array}$ & $\begin{array}{l}3,39 * * * \\
1,83 * * *\end{array}$ & $\begin{array}{c}1,66 * * * \\
1,16\end{array}$ \\
\hline $\begin{array}{l}\text { Nivel educativo del PSH de origen } \\
\text { (Ref. Hasta secundaria incompleta) } \\
\text { Secundario completo } \\
\text { Superior completo }\end{array}$ & & $\begin{array}{l}4,57 * * * \\
7,21 * * *\end{array}$ & $\begin{array}{l}4,37 * * * \\
6,71 * * *\end{array}$ & $\begin{array}{l}4,31 * * * \\
6,61 * * *\end{array}$ & $\begin{array}{l}1,80 * * * \\
3,69 * * *\end{array}$ \\
\hline $\begin{array}{l}\text { Lugar de nacimiento (Ref. CdMx) } \\
\text { Frontera } \\
\text { Bajío-Occidente } \\
\text { Centro } \\
\text { Golfo-Sur }\end{array}$ & & & $\begin{array}{l}0,54 * * * \\
0,47 * * * \\
0,52 * * * \\
0,45 * * *\end{array}$ & $\begin{array}{l}0,53 * * * \\
0,46 * * * \\
0,51 * * * \\
0,44 * * *\end{array}$ & $\begin{array}{c}0,74 \\
0,68 * \\
0,66 * \\
0,63 * * \\
\end{array}$ \\
\hline $\begin{array}{l}\text { Cohorte de nacimiento (Ref. 52-59) } \\
\text { Nacidos entre } 1960 \text { y } 1968 \\
\text { Nacidos entre } 1969 \text { y } 1977 \\
\text { Nacidos entre } 1978 \text { y } 1986\end{array}$ & & & & $\begin{array}{l}1,14 \\
1,02 \\
1,16\end{array}$ & $\begin{array}{c}0,78 \\
0,69 * \\
0,63 * *\end{array}$ \\
\hline $\begin{array}{l}\text { Constante } \\
\text { Pseudo } \mathrm{R}^{2}\end{array}$ & $\begin{array}{c}0,11 * * * \\
0.11\end{array}$ & $\begin{array}{c}0,10 * * * \\
0.16\end{array}$ & $\begin{array}{c}0,20 * * * \\
0.17\end{array}$ & $\begin{array}{c}0,19 * * * \\
0.17\end{array}$ & $\begin{array}{l}1,55 \\
0.07 \\
\end{array}$ \\
\hline $\mathrm{N}$ & 11.030 & 9.985 & 9.985 & 9.985 & 3.109 \\
\hline
\end{tabular}

Notas: (1) $0=$ No accedió a títulos de nivel superior; $1=$ Logró título de nivel superior.

$* * * \mathrm{p}<0,001 ; * *<0,01 ; * \mathrm{p}<0,05, \mathrm{n} / \mathrm{c}$ : no considerada.

Fuente: elaboración propia con base en MMSI, INEGI 2016.

En el modelo 1 de México se observa que el origen de clase social también se asocia significativamente con la probabilidad de obtener un título de nivel superior. Al introducir el nivel educativo de origen en el modelo 2, también observamos, como en el caso argentino, una disminución del efecto de la clase social de origen lo que pone en evidencia la asociación entre ambas variables adscriptas. A su vez, el origen educativo aporta un efecto significativo controlando por la clase social de origen, incluso de mayor magnitud respecto al reportado en la clase social. Así, los PSH con orígenes familiares educativos altos (superior completo), tienen 7,21 más oportunidades de obtener un título universitario o terciario con respecto a los hogares con el nivel educativo más bajo, y la probabilidad se reduce a 4,57 veces entre el secundario completo y el secundario incompleto. Entre el modelo 1 y el modelo 2 también observamos un aumento en el valor del $\mathrm{R}^{2}$ de Nagelkerke $(0,11$ a 0,16), un indicador de la importancia del nivel educativo de origen como mecanismo para diferenciar la probabilidad de llegar a graduarse del nivel superior. 
En el modelo 3 se introduce la región en la que se residía a los 14 años (como proxy del lugar de nacimiento). Por un lado, observamos que las chances relativas de las primeras dos variables se mantienen prácticamente en los mismos valores, además que la $\mathrm{R}^{2}$ permanece en la misma magnitud. Por otro lado, encontramos que existe una diferencia estadísticamente significativa entre haber residido en la Ciudad de México a los 14 años frente al resto de regiones del país, que tienen menos probabilidad de haber llegado a completar los estudios superiores (todas las chances relativas son menores a 1), aunque con un efecto neto moderado.

Con respecto al modelo 4 observamos una tendencia similar a la observada en Argentina: las variables introducidas en los pasos anteriores tienen un efecto prácticamente igual, con los mismos niveles de significancia estadística, y el valor de ajuste del modelo no muestra cambios sustantivos. Además, al considerar a la población completa, la cohorte de nacimiento no muestra significación estadística.

Finalmente, en el modelo que incorpora únicamente la población con secundario completo, se observan algunos cambios interesantes. En primer lugar, disminuye el efecto del origen de clase y el origen educativo. En segundo lugar, la región de nacimiento pierde la significación estadística (excepto la región Golfo-sur, aunque con un nivel de significación al 90\%). En tercer lugar, la perspectiva temporal arroja un resultado similar al caso argentino: si bien el porcentaje de PSH con título de nivel superior aumenta a través del tiempo, las oportunidades para graduarse son paulatinamente menores conforme se llega a la cohorte más joven.

En síntesis, al considerar a la población total en ambos países observamos que en Argentina la probabilidad de finalizar el nivel superior de educación es menor en la última cohorte controlando por origen de clase social, nivel educativo de la familia de origen y lugar de nacimiento, en cambio en México se mantiene constante a pesar de una mayor expansión de la graduación en general. Sin embargo, al considerar a la población que finalizó el secundario la pauta empeora para México, las dos últimas cohortes muestran menores probabilidades de logro educativo y en Argentina se mantiene la desventaja sólo en la última cohorte. 


\section{Conclusiones}

La indagación realizada en perspectiva comparativa entre Argentina y México buscó conocer de manera exploratoria la relación entre el nivel de expansión de la población con nivel de educación superior y los cambios en el tiempo en el peso del origen social familiar en la desigualdad de oportunidades de logro. Es decir, si las posibilidades de graduación dependen más de esfuerzos personales, capacidades, habilidades y estrategias de apoyo familiar o si se incrementó en el tiempo el peso de factores adscriptos: heredados y no elegidos.

Hemos observado que en ambos países la concreción de credenciales educativas de nivel superior muestra una pauta de amplia desigualdad de oportunidades por orígenes sociales. En un primer análisis descriptivo según variables de tipo adscriptivo observamos que, a mayor clase social y nivel educativo de origen, así como al haber nacido en CABA o en la Ciudad de México, mayor es la proporción de personas con título universitario o terciario.

Al introducir una dinámica temporal a través de cohortes observamos una diferencia significativa entre ambos países. En Argentina, en términos generales el porcentaje de población con nivel superior completo se mantiene casi constante a través de las mismas. En cambio, en México, la expansión de la universidad de las últimas décadas se refleja en un volumen mayor de graduados universitarios y terciarios en las cohortes más recientes.

En Argentina, en un contexto de escasa expansión del volumen de población con nivel educativo superior completo, hubo un incremento progresivo a través de las cohortes en las brechas de desigualdad según origen social familiar tanto de clase social como nivel educativo. Las clases medias, en particular la clase de servicios o empleadores, se apropiaron más de las oportunidades educativas. En México, a pesar del incremento del volumen de población con nivel educativo superior completo, la tendencia al incremento de la desigualdad según origen social familiar se mantiene. Estas pautas en conjunto sugieren el incremento de mecanismos de cierre social en ambos países que limitan la concreción de logros educativos para quienes provienen de hogares de clase popular y climas educativos más bajos.

Al introducir un modelo de regresión logística multivariada por pasos nos permitió profundizar en el efecto neto de las variables mencionadas, así como examinar con mayor profundidad la dinámica temporal en ambos países: 
i. La variable nivel educativo del hogar de origen es la que mayor influencia tiene en las chances relativas de graduación del nivel superior en ambos países.

ii. El peso de la clase social de origen en las chances relativas de obtener títulos de nivel superior disminuye al incorporar otras variables de tipo adscriptivas, en particular, el clima educativo del hogar de origen, pero no desaparece, incluso mantiene su influencia en niveles elevados en ambos países. Esta pauta implica que el origen de clase y el clima educativo del hogar están interrelacionadas evidenciado en un efecto bruto conjunto y en parte también expresan mecanismos distintos de transmisión de oportunidades desiguales.

iii. El lugar de nacimiento tiene peso propio en la desigualdad de oportunidades educativas en ambos países que coindice con un patrón histórico de desarrollo desequilibrado tanto en Argentina como en México en favor de la ciudad-capital, donde se concentran las oportunidades educativas de cada país. En ambos países, haber nacido en CABA o Ciudad de México implica mayores ventajas para obtener un título de nivel superior independientemente de la clase social y el nivel educativo del hogar de origen y la cohorte. Para esta pauta arriesgamos una interpretación: en estos territorios, una sociabilidad con mayor gravitación de clases medias (no sólo como clase de origen) configura mayores expectativas y aspiraciones de finalizar carreras de nivel superior y una mayor oferta universitaria permitiría concretarlas.

iv. El análisis por cohortes mostró diferencias entre ambos países, pero vinculadas a una pauta común. En Argentina, controlando por las variables adscriptas señaladas, se observa una disminución de las probabilidades de finalizar el nivel de educación superior en la última cohorte. En México, en cambio, las probabilidades de obtener logros educativos de nivel superior se mantienen constantes en el tiempo. Detrás de estos resultados hay una pauta común entre ambos países: el crecimiento mayor de las probabilidades de graduación de la población con origen en las clases medias privilegiadas. En Argentina, ocurre en un contexto de estancamiento del volumen de graduación, por lo que el crecimiento de la probabilidad de logro de las clases medias privilegiadas se produce a expensas de la clase intermedia, mientras que en México, la expansión de la graduación de las clases medias privilegiadas es el motor del crecimiento de la graduación en el conjunto de la población.

v. Los resultados del modelo de regresión acotado a la población que tiene nivel secundario completo y que, por tanto, estaba en condiciones de ingresar a la universidad, muestran cierta similitud entre ambos países. En Argentina, el nivel de desigualdad de oportunidades 
según los factores adscriptos señalados disminuye, pero todas conservan efectos significativos. El análisis en perspectiva temporal muestra que se mantiene la desventaja de la última cohorte. Estas pautas consolidan los resultados previos del estudio de Dalle, Boniolo, Estévez Leston y Carrascosa (2018) centrado en la desigualdad de oportunidades de logro del nivel universitario. De manera preliminar, estos resultados son indicativos de que no estaría actuando un fuerte efecto de selectividad, según el cual, entre aquellos estudiantes con orígenes sociales más bajos que atravesaron con éxito transiciones educativas (del primario al secundario y del secundario al nivel superior) se reduce, hasta casi desaparecer, el efecto de los factores adscriptos en el logro de títulos universitarios o terciarios.

En México, el efecto de factores adscriptos disminuye, sin embargo, al considerar las cohortes se observa un incremento progresivo de la desigualdad de oportunidades en el tiempo. Esta pauta sugiere que en la actualidad la finalización de la escuela secundaria es más masiva y vuelven a emerger con más fuerza clivajes de desigualdad de oportunidades entre quienes emprenden estudios de nivel superior. En cambio, en cohortes anteriores, las personas de origen de clases medias bajas o de clase popular que finalizaban la escolaridad media y estaban en condiciones de acceder al nivel superior por motivación, capacidades, habilidades y entorno social eran más cercanas a sus pares de clases medias privilegiadas.

En suma, las pautas observadas nos permiten sugerir, en términos de Hout y Raftery (1993), que en ambos países el nivel de expansión educativa, en Argentina una expansión que se desarrolló más tempranamente y luego se estancó y en México una expansión más tardía pero progresiva, habría sido insuficiente para reducir la desigualdad de oportunidades de graduación del nivel superior vinculadas al origen social familiar ${ }^{3}$. Más bien el sistema de educación superior en ambos países ha logrado un nivel de expansión que hasta el momento permitió graduar en mayor proporción a población con origen en las clases medias, en particular sus fracciones más privilegiadas.

En México, si bien las probabilidades de obtener un título de nivel superior han aumentado paulatinamente para la población en su conjunto, la pauta de aumento progresivo de la

\footnotetext{
${ }^{3}$ En Argentina, el principal problema no es de acceso a la educación superior, de hecho, tiene un nivel de matrícula elevado, el principal problema es la permanencia y la graduación. Una política pública en el período 2003-2015 fue la creación de nueve universidades nacionales, cinco de ellas en barrios obreros y clase media baja del conurbano bonaerense. El crecimiento de la matrícula en dichas universidades ha sido importante (de 5.641 a 42.276 estudiantes entre 2010 y 2014). Esta medida, sin dudas, ha sido positiva para expandir la oferta académica y acercarla a sectores postergados. Por la escasa cantidad de años que transcurrieron desde su creación aún es prematuro analizar la tasa de graduación.
} 
desigualdad a través de las cohortes (en particular al considerar la población que finalizó la escuela secundaria y estuvo en condiciones de acceder al nivel superior) entre la población que finalizó el nivel secundario y por lo tanto estuvo en condiciones de ingresar al nivel superior, apuntaría a caracterizar un sistema en el que los más aventajados socialmente tienen mayores posibilidades de sacar provecho del aumento de la oferta educativa.

Los casos de Argentina y México muestran que el aumento de desigualdad de oportunidades no es estrictamente un problema de restricción de la oferta de educación de nivel superior, porque la matrícula se incrementó en ambos países. Es muy posible que el crecimiento de la desigualdad de condiciones de vida entre las clases sociales en el último cuarto del siglo XX en ambos países haya repercutido en el incremento de la desigualdad de oportunidades de logro educativo de nivel superior, en particular al considerar la población que finalizó la escuela media. En un contexto de polarización de las posiciones de clase y de mayor segregación socio-residencial, la población con orígenes en las clases populares enfrenta mayores obstáculos para acceder, permanecer y lograr títulos de nivel superior.

\section{Bibliografía}

ALCOBA, M. (2014). La dimensión social del logro individual. Desigualdad de oportunidade educativas y laborales en Argentina. México DF: FLACSO México.

ANUIES, 2017. Anuarios Estadísticos de Educación Superior. México: Asociación Nacional de Universidades e Instituciones de Educación Superior.

ARIZA, M. SOLÍS, P. (2009). “Dinámica socioeconómica y segregación espacial en tres áreas metropolitanas de México, 1990 y 2000”, Estudios Sociológicos, vol. XXVII, núm. 79.

BALÁN, J. BROWNING, H. L. JELIN, E. (1977). El hombre en una sociedad en desarrollo: movilidad geográfica y social en Monterrey, México: Fondo de Cultura Económica.

BINDER, M. WOODRUFF, C. (2002). "Inequality and intergenerational mobility in schooling: the case of Mexico", Economic Development and Cultural Change, 50(2), 249-267.

BONIOLO, P. ESTÉVEZ LESTON, B. (2017). "The effect of territory in social mobility of households in the Región Metropolitana de Buenos Aires", Cuadernos Geográficos (Vol. 56). 
BONIOLO, P. NAJMÍAS, C. (2018). “Abandono y rezago escolar en Argentina: una mirada desde las clases sociales", Tempo Social, (En Prensa).

BOURDIEU, P. PASSERON, J. C. (2003[1964]). Los herederos: los estudiantes y la cultura, Buenos Aires: Siglo Veintiuno.

CORTÉS, F. y LATAPÍ, A. (2007). “Movilidad social en el México urbano”, En: R.

Franco, A. LEÓN, y R. ATRIA (Coords.), Estratificación y movilidad social en América Latina: transformaciones estructurales de un cuarto de siglo, Pp. 409-445, Santiago de Chile: Lom Ediciones/cepal-gtz.

DALLE, P. (2018). “Climbing up a Steeper Staircase: Intergenerational Social Mobility across Birth Cohorts in Argentina (2003-2010)", Research in Social Stratification and Mobility (54), 21-35. Recuperado de: https://doi.org/10.1016/j.rssm.2017.12.002

DAlle, P. BONIOLO, P. ESTÉVEZ LESTON, B. CARRASCOSA, J. (2018). "Desigualdad de oportunidades de graduación universitaria en Argentina (1965-2015): Efectos del territorio, la clase social de origen y el nivel educativo familiar", Revista Ciudadanías, Buenos Aires, Universidad Tres de Febrero.

DE HOYOS, R. (2010). "Educación y movilidad social en México”, En Serrano, Julio y Florencia Torche (eds.), Estudios de movilidad social en México, Ciudad de México: Centro de Estudios Espinosa Yglesias, pp. 71-133.

FACHELLI, S. DERTEANO, M. TORRENTS, P. (2015). "Un análisis comparado de las desigualdades de acceso a la universidad en Argentina, España y México en 2013”, 127.

GERMANI, G. SAUTU, R. (1965). Regularidad y origen social en los estudiantes universitarios, Trabajos e Investigaciones del Instituto de Sociología. Buenos Aires: Universidad de Buenos Aires.

GOLDTHORPE, J. (2016). "Social class mobility in modern Britain: changing structure, constant process", Journal of the British Academy, (4), 89-111.

GUADAGNI, A. (2018). “A un siglo de la reforma universitaria.”, Informe del Centro de Estudios de la Educación Argentina, Año 7 - No 71, Buenos Aires: Universidad de Belgrano.

HOUT, M. RAFTERY, A. E. (1993). "Maximally maintained inequality: Expansion, reform, and opportunity in Irish education", 1921-75. Sociology of education, 41-62.

JORRAT, J. R. (2010). "Logros educacionales y movilidad educacional intergeneracional en Argentina”, Desarrollo Económico, 49(196), 573-604.

JORRAT, J. R. (2016). “De tal padre... ¿tal hijo?”: Estudios sobre Movilidad Social en Argentina. (J. R. Jorrat, Ed.) Buenos Aires: Dunken. 
JORRAT, J. R. BENZA, G. (2016). "Movilidad intergeneracional en Argentina, 20032010”, En: Boado, M. y Solís, P. (ed.) Y sin embargo se mueve... Estratificación social y movilidad intergeneracional en América latina, México: Centro de Estudios Espinosa Yglesias y El Colegio de México.

KAZTMAN, R. (2001). "Seducidos y abandonados: el aislamiento social de los pobres urbanos", Revista de la CEPAL, Buenos Aires, (75), 171-189.

LUCAS, S.R. (2001). "Effectively Maintained Inequality: Education Transitions, Track Mobility, and Social Background Effects”, American Journal of Sociology, 106 (6).

MALDONADO-MALDONADO, A. MEJÍA, G. (2018). "Higher education systems and institutions, Mexico", En: Shin, J.C. y Texeira, P. (ed.), Encyclopedia of International Higher Education Systems and Institutions, Dordrecht: Springer

MARE, R. (1980). "Social Background and School Continuation Decisions", Journal of the American Statistical Association. 75, 293-305.

MASSEY, D. DENTON, N. (1988). “The Dimensions of Residential Segregation”, Social Forces. 67(2).

OCDE. (2016). Panorama de la educación. Indicadores de la OCDE 2016. Informe Español. Ministerio de Educación, Cultura y Deporte.

PLOTNO, G. (2015). Universidad, clase social y educación familiar: acceso y graduación en el nivel superior en Argentina (Tesis de Maestría), Facultad de Ciencias Sociales, Buenos Aires.

QUARTULLI, D. (2016). Efectos de origen clase en la Argentina (1955-2001), (Tesis de Doctorado). Universidad de Buenos Aires, Buenos Aires, Argentina.

RODRÍGUEZ, J. ARRIAGADA, C. (2004). "Segregación residencial en la ciudad latinoamericana", Revista Eure, Chile, Vol. XXIX, (89), 5-24.

RODRÍGUEZ, R. (1998). "Evolución reciente de la matrícula universitaria.Datos y reflexiones”, En: Muñoz García, H. y Rodríguez Gómez, R. (coords.), Escenarios para la universidad contemporánea, Pensamiento Universitario, núm. 83, México: CESUUNAM (Pp. 33-54).

RODRÍGUEZ, S. A. (2016). "Logros educativos en el nivel de instrucción superior y movilidad educacional intergeneracional en Argentina”, Sociológica (México), 31(88), $167-200$. Recuperado de: http://www.scielo.org.mx/scielo.php?Script=sci_arttext\&pid=S01870173201600020017 SOLÍS, P. (2016). "Estratificación social y movilidad de clase en México a principios del siglo XXI", en Solís, P. y M. Boado Y sin embargo se mueve...Estratificación social y 
movilidad intergeneracional de clase en América Latina, Centro de Estudios Espinosa Iglesias y El Colegio de México: México D.F.

SOLÍS, P. PUGA, I (2011). "Efectos del nivel socioeconómico de la zona de residencia sobre el proceso de estratificación social en Monterrey", Estudios demográficos y urbanos, México, 6(2).

SOLÍS, P. CORTÉS, F. (2009). "La movilidad ocupacional en México: rasgos generales, matices regionales y diferencias por sexo", Tramas familiares en el México contemporáneo. Una perspectiva sociodemográfica, México, Instituto de Investigaciones Sociales-UNAM, El Colegio de México, 395-435.

TORCHE, F. (2010). "Cambio y persistencia de la movilidad intergeneracional en México", En Serrano, Julio y Florencia Torche (eds.), Estudios de movilidad social en México, Ciudad de México: Centro de Estudios Espinosa Yglesias, pp. 71-133.

YALONETZKY, G. (2017). "Movilidad intergeneracional de la educación en México: un análisis de cohortes filiales y sexo", Sobre México. Revista de Economía, 3(1), 66-87. 